\title{
Giant lymph node hyperplasia of the mediastinum and refractory anaemia
}

\author{
C. G. GEARY AND H. FOX \\ From the Department of Haematology, Manchester Royal Infirmary and the Department of Pathology, \\ University of Manchester, UK
}

SUMMARY An example is described of the syndrome of refractory anaemia in association with the plasma cell variant of giant lymph node hyperplasia of the mediastinum; the anaemia responded to removal of the lymphoid mass. The entity of giant lymph node hyperplasia is discussed and its relationship to the haematological syndrome is considered.

We report an example of the rare syndrome of severe anaemia in association with the plasma cell variant of giant lymph node hyperplasia of the mediastinum, this being, as far as we are aware, the first such case to be recorded in this country.

\section{Case report}

A female student aged 21 gave a history of lassitude for several months; she had also noted menorrhagia but there were no systemic symptoms such as fever, weight loss, or anorexia. Physical examination showed mucosal pallor but there were no other abnormal signs.

A chest radiograph demonstrated a large upper mediastinal shadow, and other investigations showed a haemoglobin of $7.2 \mathrm{~g} / \mathrm{dl} ; \mathrm{MCV} 62 \mathrm{fl}$; MCHC 32\%; white blood count 6.4 $\times 10^{9} / 1$ (neutrophils $72 \%$, lymphocytes $20 \%$, monocytes $8 \%$ ); platelets $327 \times 10^{9} / 1$; serum albumin $37 \mathrm{~g} / 1$; serum globulin $52 \mathrm{~g} / 1$; serum electrophoresis showed a polyclonal increase in globulins; serum iron $2 \cdot 148 \mu \mathrm{mol} / \mathrm{l}(12 \mu \mathrm{g} / 100 \mathrm{ml})$; TIBC $62 \cdot 3 \mu \mathrm{mol} / 1$ $(348 \mu \mathrm{g} / 100 \mathrm{ml})$; serum ferritin $201 \mu \mathrm{g} / 1(201 \mathrm{ng} / \mathrm{ml})$. Bone marrow aspiration yielded a cellular sample showing granulocytic hyperplasia and an increased content $(8 \%)$ of mature plasma cells; erythropoiesis and thrombopoiesis were orderly, but there was a striking increase in RE cell iron. The liver appeared normal on biopsy, and a gallium scan showed no evidence of generalised lymphadenopathy.

A presumptive diagnosis of malignant lymphoma was made but at this stage the patient mentioned

Received for publication 16 January 1978 that a routine chest $x$-ray six years previously had also been abnormal; these films were obtained, and it was apparent that there had been no significant change in the size of the mediastinal mass over this period. It therefore appeared that the mass was unlikely to be neoplastic but as blood transfusion was required to maintain the patient's haemoglobin level a thoracotomy was undertaken (Mr H.F. M. Bassett). A mass was found in the superior mediastinum in close apposition to the trachea and was removed.

\section{PATHOLOGICAL FINDINGS}

The specimen received was a rounded mass with a bosselated surface; it measured $6.2 \times 4.4 \times 3.6 \mathrm{~cm}$. On section there was a slightly lobulated appearance, and the mass was formed of homogenous, moderately firm, pinkish-grey tissue.

On histological examination the mass was seen to consist of lymphoid tissue, in which the normal nodal architecture had been largely obliterated by a profusion of follicles; in some areas, however, a peripheral subcapsular sinus was still discernible (Fig. 1). A majority of the follicles were moderately large, contained well-formed germinal centres, and had a clearly defined, dense peripheral mantle of lymphocytes (Fig. 2). Many of the follicles were penetrated by vessels, seen either in transverse section running through the centre of the follicle or in longitudinal section coursing into the follicle radially; only a few of these vessels were noticeably thick-walled, and hyalinisation was rare. There was a conspicuous proliferation of small vessels in the interfollicular spaces (Fig. 3) which also contained, in many areas, sheets of mature plasma cells (Fig. 4).

A diagnosis of plasma cell variant of giant lymph node hyperplasia was made. 


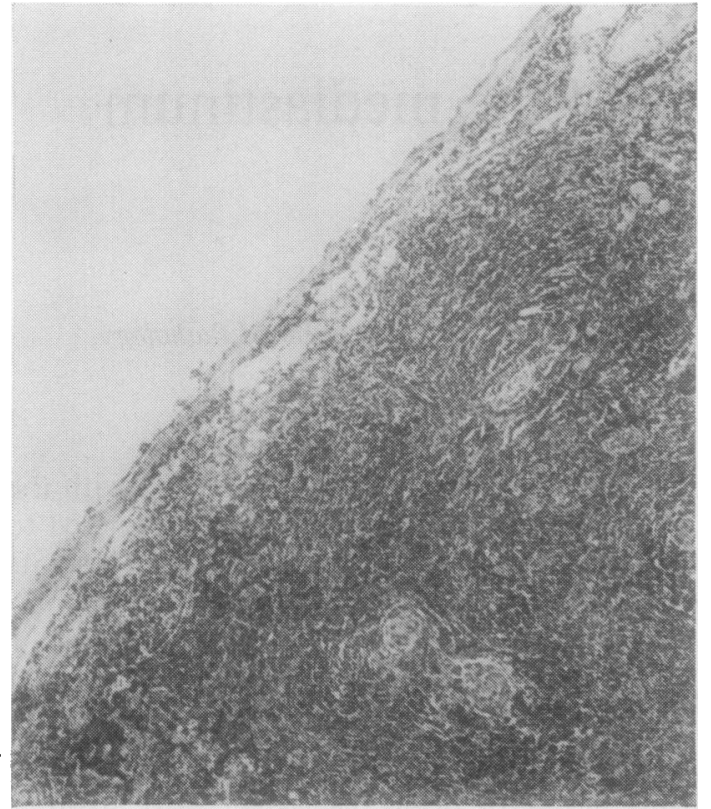

Fig. 1 Low-power view of the edge of the lymphoid mass. The remnants of a subcapsular sinus can be discerned. (Haematoxylin and eosin $\times 40$ )

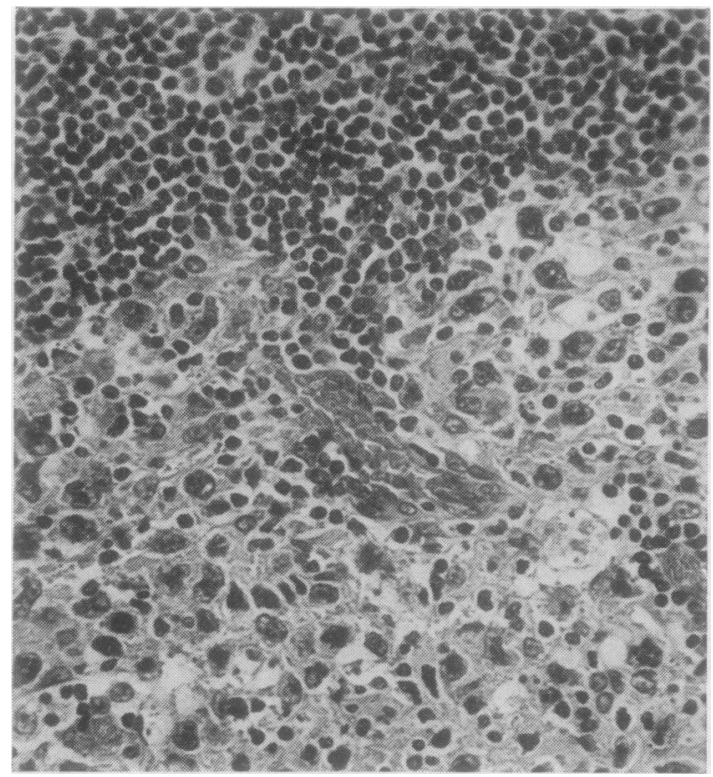

Fig. 2 High-power view of a follicle. This consists of a germinal centre with a mantle of lymphocytes, and a vessel can be seen running into the centre of the follicle. ( $H$ and $E \times 380$ )

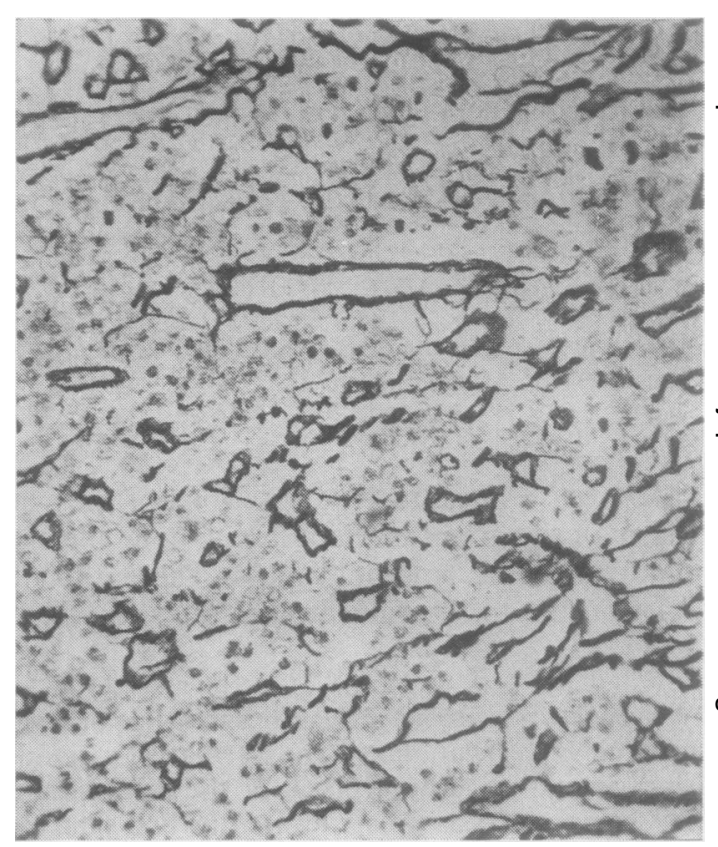

Fig. 3 An interfollicular space stained for reticulin.

There is a profusion of small vessels. (Gomori $\times 255)$

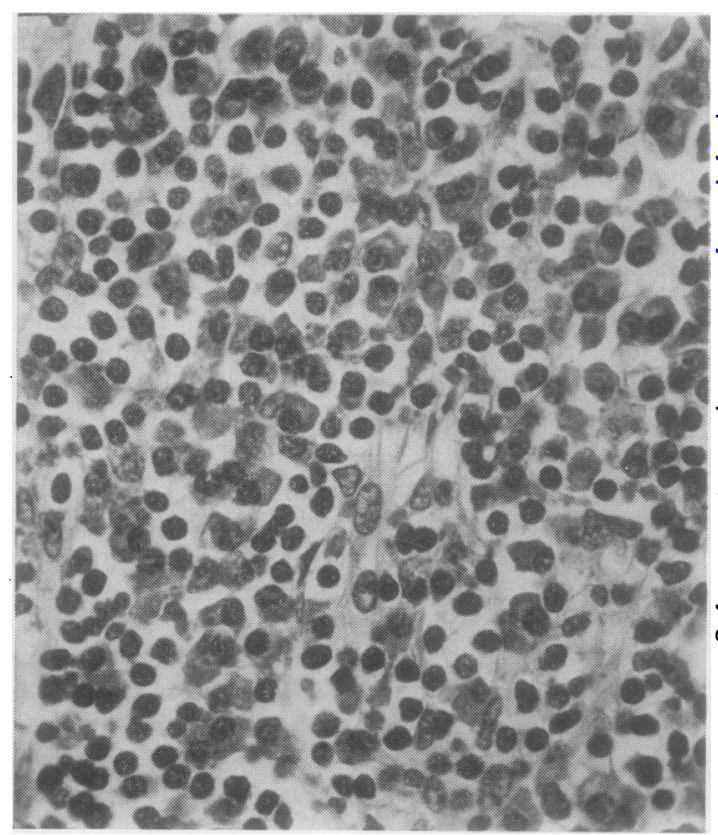

Fig. 4 An interfollicular space which contains large numbers of mature plasma cells. $(H$ and $E \times 340)$ 


\section{PROGRESS}

After removal of the mass the patient's clinical condition improved, and six months later her haemoglobin was $12.4 \mathrm{~g} / \mathrm{dl}$ and the serum globulin level had fallen to normal.

\section{Discussion}

Giant lymph node hyperplasia was first defined by Castleman et al. (1956) as an asymptomatic, massive hyperplasia of the mediastinal lymph nodes, producing a mass that often mimics, both radiologically and on gross pathological examination, a thymoma. Since then a wide variety of synonyms have been applied to this form of nodal hyperplasia; these include angiofollicular lymph node hyperplasia, lymphonodal hamartoma, angiomatous lymph node hamartoma, benign giant lymphoma, and follicular lymphoreticuloma, this plethora of names being engendered by different concepts of its pathogenesis.

Giant lymph node hyperplasia is uncommon but not excessively rare for Keller et al. (1972) were able to review 81 cases, of which 61 were from their own practice and 20 were culled from the literature. As experience has widened, it has become clear that lesions of this type are not confined to the mediastinum but can occur elsewhere, such as in the neck, axilla, retroperitoneum, and mesentery. The characteristic histological features of giant lymph node hyperplasia, as described originally by Castleman et al. (1956) and confirmed subsequently in many other reports, are the presence-often in what can still be recognised as a lymph node-of numerous small lymphoid follicles. These contain thick-walled, frequently hyalinised, vessels, around which the central follicular cells tend to be arranged in a tight concentric 'onion-skin' pattern; the interfollicular spaces also contain numerous vessels of the same type, with a variable number of immunoblasts, eosinophils, and plasma cells. The majority of cases of giant lymph node hyperplasia conform to this 'hyaline-vascular' pattern, but a plasma cell variant has also been described in which, as in the case reported here, the lymphoid follicles are large and reactive, the vascular component is less marked or even absent, and the interfollicular spaces are obiliterated by sheets of plasma cells (Keller et al., 1972). This 'plasma cell variant' accounts for about $10 \%$ of cases of giant lymph node hyperplasia, though occasional examples of a form intermediate between the two main varieties have been noted; rarely, there may be a hyaline-vascular pattern in one area of a mass and a plasma cell pattern elsewhere.

The nature of this lesion remains obscure; Keller et al. (1972) reviewed critically the claims that it is either a hamartoma (Abell, 1957; Lattes and
Pachter, 1962) or a malignant lymphoma (Zettergren, 1961; Fisher et al., 1970), concluded that little evidence existed for either assertion, and suggested that it represents an exaggerated hyperplastic reaction of lymph nodes to an antigenic stimulus. Dorfman and Warnke (1974), while agreeing that, in most instances, the lesion develops in a node, noted examples in sites such as the broad ligament and soft tissues of the shoulder, in which microscopic examination of the mass did not reveal any evidence of a pre-existing nodal structure.

Giant lymph node hyperplasia is usually either asymptomatic and revealed only by routine chest $x$ ray or produces mechanical symptoms due to the presence of a tumour-like mass. Lee et al. (1965), however, described a patient in whom giant lymph node hyperplasia was associated with a refractory anaemia, which remitted completely after removal of the lymphoid mass. Seven years later Keller et al. (1972) were able to collect from their own experience and from the literature 12 cases of this syndrome, and additional examples have been recorded by Sethi and Kepes (1971), Boxer et al. (1972), Kahn et al. (1973), Namba et al. (1973), Dorfman and Warnke (1974), Ende et al. (1975), Burgert et al. (1975), and Notomi et al. (1976). The anaemia, which is always refractory to any form of treatment apart from removal of the nodal mass, may be normocytic and normochromic or microcytic and hypochromic: it commonly has the features of 'the anaemia of chronic disorders', which, as described by Cartwright and Lee (1971), is characterised by an abnormal avidity of the RE cells for transferrin-bound iron. Additional features of this syndrome vary but have included fever, an elevated ESR, hypergammaglobulinaemia, hypoalbuminaemia, thrombocytosis, leucocytosis, and, in children, retardation of growth; in some patients there has been an elevated plasma alkaline phosphatase and an increased bromsulphalein retention but in only one has jaundice occurred, this being, rather surprisingly, of the obstructive type (Notomi et al., 1976).

The association between a haematological syndrome and giant lymph node hyperplasia is confined to the plasma cell variant of this condition and does not occur with the hyaline-vascular form. The only clue as to the nature of this association has come from Burgert et al. (1975), who used an exhypoxic polycythaemic mouse assay system to demonstrate that preoperative serum from their patient contained a factor which inhibited erythropoietin activity and decreased the uptake of ${ }^{59} \mathrm{Fe}$; this serum factor had disappeared by the sixth day after removal of the mass, but unfortunately the anti-erythropoietin activity of the abnormal lymphoid tissue was not estimated.

The natural history of this disorder is probably 
always benign but, because of its rarity, it is usually diagnosed before operation as being either a malignant lymphoma or a thymoma with an associated haematological abnormality. The pathological distinction between these conditions and giant lymph node hyperplasia does not, however, present any great difficulty.

\section{References}

Abell, M. R. (1957). Lymphnodal hamartoma versus thymic choristoma of pulmonary hilum. Archives of Pathology, 64, 584-588.

Boxer, L. A., Boxer, G. J., Flair, R. C., Engstrom, P. F., and Brown, G. S. (1972). Angiomatous lymphoid hamartoma associated with chronic anemia, hypoferremia, and hypergammaglobulinemia. Journal of Pediatrics, 81, 66-70.

Burgert, E. O. Jr., Gilchrist, G. S., Fairbanks, V. F., Lynn, H. B., Dukes, P. P., and Harrison, E. G., Jr. (1975). Intra-abdominal, angiofollicular lymph node hyperplasia (plasma-cell variant) with an antierythropoietic factor. Mayo Clinic Proceedings, 50, 542-546.

Cartwright, G. E., and Lee, G. R. (1971). The anaemia of chronic disorders. British Journal of Haematology, 21, 147-152.

Castleman, B., Iverson, L., and Pardo Menendez, V. (1956). Localized mediastinal lymph-node hyperplasia resembling thymoma. Cancer, 9, 822-830.

Dorfman, R. F., and Warnke, R. (1974). Lymphadenopathy simulating the malignant lymphomas. Human Pathology, 5, 519-550.

Ende, J. van den, Kahn, L. B., and Jacobs, P. (1975). Giant lymph node hyperplasia with haematological abnormality. South African Medical Journal, 49, 170.

Fisher, E. R., Sieracki, J. C., and Goldenberg, D. M. (1970). Identity and nature of isolated lymphoid tumors (so-called nodal hyperplasia, hamartoma, and angiomatous hamartoma), as revealed by histologic, electron microscopic, and heterotransplantation studies. Cancer, 25, 1286-1300.

Kahn, L. B., Ranchod, M., Stables, D. P., King, H., and Yudelman, I. (1973). Giant lymph node hyperplasia with haematological abnormalities. South African Medical Journal, 47, 811-816.

Keller, A. R., Hochholzer, L., and Castleman, B. (1972). Hyaline-vascular and plasma-cell types of giant lymph node hyperplasia of the mediastinum and other locations. Cancer, 29, 670-683.

Lattes, R., and Pachter, M. R. (1962). Benign lymphoid masses of probable hamartomatous nature. Cancer, 15, 197-214.

Lee, S. L., Rosner, F., Rivero, I., Feldman, F., and Hurwitz, A. (1965). Refractory anemia with abnormal iron metabolism: its remission after resection of hyperplastic mediastinal lymph nodes. New England Journal of Medicine, 272, 761-766.

Namba, M., Ogura, T., Hirao, F., Yamamura, Y., and Mori, T. (1973). Mediastinal lymph node hyperplasia: a report of two cases, hyaline-vascular type and plasmacell type. Medical Journal of Osaka University, 23, 239247.

Notomi, A., Iwamoto, Y., and Kikuchi, M. (1976). Giant lymph node hyperplasia with fever, anemia, hypergammaglobulinemia and jaundice. Acta Haematologica Japonica, 39, 11-19.

Sethi, G., and Kepes, J. J. (1971). Intrathoracic angiomatous lymphoid hamartomas; a report of three cases, one of iron refractory anemia and retarded growth. Journal of Thoracic and Cardiovascular Surgery, 61, 657664.

Zettergren, L. (1961). Probably neoplastic proliferation of lymphoid tissue (follicular lympho-reticuloma). Acta Pathologicaet Microbiologica Scandinavica, 51, 113-126.

Requests for reprints to: Dr H. Fox, Department of Pathology, University of Manchester, Stopford Building, Oxford Road, Manchester M13 9PT. 